Article

\title{
Development of a Monitoring Strategy for Laser-Textured Metallic Surfaces Using a Diffractive Approach
}

\author{
Sascha Teutoburg-Weiss ${ }^{1, *}$, Bogdan Voisiat ${ }^{1}$ (D), Marcos Soldera ${ }^{1,2}$ (D) \\ and Andrés Fabián Lasagni 1,3 \\ 1 Institute of Manufacturing Science and Engineering, Technische Universität Dresden, \\ 01062 Dresden, Germany; bogdan.voisiat@tu-dresden.de (B.V.); \\ marcos.soldera@mailbox.tu-dresden.de (M.S.); andres_fabian.lasagni@tu-dresden.de (A.F.L.) \\ 2 Probien-Conicet, Dto. de Electrotecnia, Universidad Nacional del Comahue, Buenos Aires 1400, \\ Neuquén 8300, Argentina \\ 3 Department, Fraunhofer Institute of Material and Beam Technology IWS, Winterbergstr. 28, \\ 01277 Dresden, Germany \\ * Correspondence: sascha.teutoburg-weiss@tu-dresden.de
}

Received: 12 November 2019; Accepted: 17 December 2019; Published: 20 December 2019

\begin{abstract}
The current status of research around the world concurs on the powerful influence of micro- and nano-textured surfaces in terms of surface functionalization. In order to characterize the manufactured topographical morphology with regard to the surface quality or homogeneity, major efforts are still required. In this work, an optical approach for the indirect evaluation of the quality and morphology of surface structures manufactured with Direct Laser Interference Patterning (DLIP) is presented. For testing the designed optical configuration, line-like surface patterns are fabricated at a $1064 \mathrm{~nm}$ wavelength on stainless steel with a repetitive distance of $4.9 \mu \mathrm{m}$, utilizing a two-beam DLIP configuration. Depending on the pulse to pulse overlap and hatch distance, different single and complex pattern geometries are produced, presenting non-homogenous and homogenous surface patterns. The developed optical system permitted the successfully classification of different pattern geometries, in particular, those showing single-scale morphology (high homogeneity). Additionally, the fabricated structures were measured using confocal microscopy method, and the obtained topographies were correlated with the recorded optical images.
\end{abstract}

Keywords: indirect surface characterization; diffraction analysis; periodic structures; direct laser interference patterning; homogeneity characterization

\section{Introduction}

It is well-known today that topographical features of surfaces with sizes in the nanometer and/or in micrometer range have a strong influence on their functionality. The most known and well-described example found in the literature is, for instance, the water repellent characteristics of several plants such as the lotus leaves [1]. Furthermore, the observed super-hydrophobic behavior of this plant was explained by the combination of a topographical pattern of features with different length-scales forming a hierarchical or multiple scale geometry as well as the control of the surface chemistry by three-dimensional epicuticular wax tubules $[1,2]$. Another famous example is the antibacterial and also hydrophobic abdominal skin of the gecko (Lucasium steindachneri), properties that are also the result of a hierarchical structured dermis [3].

Currently, an important fraction of the scientific community is investigating how to mimic natural examples with multi-scale or hierarchical surface structures, in order to provide technological materials 
with similar functions. For example, it was shown that specifically manufactured surfaces are capable of producing functionalities such as decorative elements on metals [4-6], antimicrobial properties on stainless steels $[7,8]$, drag reduction on airplane wings $[9,10]$ as well as low friction and wear on engine parts [11]. Especially, grating like textures are of interest in manufacturing diffraction optics, performing inversion of diffraction colors or for surface enhanced Raman scattering sensors [12-15]. For manufacturing such structures, robust and flexible fabrications methods are needed, providing also high resolution. Laser-based ablation methods in general fulfill these requirements, as they can be utilized directly by locally subtracting (ablating) material at the interaction region between the laser light and the material's surface. Furthermore, they can be also used on ceramics, metals, polymers, glass, and almost in every material that is capable to absorb the laser light at the utilized laser wavelength. Within these methods, Direct Laser Writing (DLW) has become an important manufacturing technique in the industry but is hardly capable to produce feature sizes down to 5-15 $\mu \mathrm{m}$ since the focal spot size is generally limited by the wavelength-specific diffraction limit. Utilizing suitable process parameters and laser pulse durations in the picosecond and femtosecond range, laser induced periodic surface structures (LIPSS) can be manufactured with sub-wavelength resolution [16-18]. An alternative method, which allows a more flexible fabrication of structures with feature sizes even in the nanometer range is Direct Laser Interference Patterning (DLIP) [19-21]. This method is based on the interference patterns that are produced when two or more coherent laser beams are overlapped on the materials surface [22]. In this way, the material can be selectively ablated (or modified) at the so-called interference maxima positions, leading to a structured surface with periodic features. Moreover, the geometry of the patterns can be controlled by changing the number of utilized beams as well as beam polarization among other parameters [19,22,23].

However, significant efforts are still necessary in order to characterize the produced topographies in terms of surface quality or homogeneity. In addition, for in-line quality controls, it is necessary to design methods capable to process the required information rapidly and thus allowing to better control the structuring process. Concerning the available methods for the characterization of surface topography, confocal and interferometric analyses are state of the art and widely common. Furthermore, in ISO 25178 part 6, several instruments and procedures are determined for topographical analysis, including stylus instruments, atomic force microscopes as example for scanning probe microscopy, phase shift microscopy, confocal microscopy, focus variation microscopy, structured light projection, stereoscopic scanning electron microscopy and area integrated scatter techniques [24]. The optical approaches mentioned above have not only the advantage of being contactless and non-destructive methods, but also, due to the nowadays available computing power, are capable of faster data acquisition compared to the stylus instruments and scanning probe microscopes [25]. However, due to the serial processing of multiple images or the scanning directives, these methods are still not fast enough to perform the task of inline monitoring or controlling routines of laser processing techniques. Purtonen et al. collected an overview of laser process monitoring approaches, showing that most of the research is developed for the melt pool evaluation and other thermal process properties of laser cladding, direct energy deposition, welding or selective laser melting [26] but not structuring. For indirect characterization of periodic structures, scatterometry is a very fast and, since it is not affected by the Abbe diffraction limit, a high-resolution technique. It is based on the diffractive behavior of reflected or transmitted light interacting with periodic features, forming intensity distributed patterns. These patterns can be then measured and compared with modeled data. For ex situ evaluation of overlay accuracy in semiconductor industry, an uncertainty of $0.5 \mathrm{~nm}$ has been showed with commercial available instruments by Smilde et al. [27]. Furthermore, scatterometry has been efficiently utilized in-line for controlling critical dimensions in lithography cluster [28] and controlling the profile of grating structures in resist trimming [29]. Recently, Kreuzer et al. also proposed the utilization of scatterometry for in-line measurement of Roll-to-Roll imprinted periodic groove widths with a precision of $40 \mathrm{~nm}$ [30]. 
Regarding the characterization of DLIP structured surfaces, recently some studies have been performed in order to determine the pattern homogeneity. For instance, using confocal microscopy, a combination of surface parameters, such as the average structure depth of the repetitive features as well as waviness factors, could be established for determining the structure quality [31]. Moreover, using power spectrum analysis of the topographies also measured by confocal microscopy or white light interferometry, additional parameters could be defined [32]. However, these methods require recording the topographical information utilizing high resolution objectives (e.g., 150X) and cannot be applied directly during the manufacturing process due to the needed measurement time of up to several seconds. In consequence, although some concepts have been already developed for characterizing surface homogeneity and topography of repetitive structures, to the best of our knowledge, there is a lack of optical monitoring approaches capable of rapidly providing information about the surface topography as well as to differentiate between homogenous and non-homogenous surface patterns.

In this work, we present an optical approach to indirectly evaluate the quality and morphology of surface structures manufactured with DLIP by recording their characteristic diffraction patterns in reflection mode when the textured surface is irradiated with a low-power coherent source of light. The recorded image by a CCD camera is processed using self-developed algorithms, in order to determine the most important parameters that can be utilized to determine the homogeneity of the patterns. Finally, the topographical results performed with confocal microscopy are compared to calculated evaluation parameters from the CCD images. As an evaluation tool, the present setup could also be helpful to extract material data and understand the underlying mechanisms by which the material forms periodic textures. For instance, recently it was shown that fracture mechanics data can be obtained by analyzing intermittent periodic patterns on the surface of brittle materials [33].

\section{Materials and Methods}

Due to the relevance of stainless steels materials in several industrial sectors (e.g., food industry [34,35], pharmacy [36], energy supply (e.g., thermal solar power plants) [37]), we focused on the treatment of electro-polished 1.430 stainless steel with a nominal thickness of $1 \mathrm{~mm}$. The used substrates were cut to $55 \mathrm{~mm} \times 85 \mathrm{~mm}$ pieces, with a surface roughness of $S_{a}=0.06 \mu \mathrm{m}$ (measured according DIN-ISO 25178 norm [38]). Before the laser treatment, all samples were cleaned using isopropanol.

The structuring process was done with a NeoLase Nd:YAG laser (Hannover, Germany), providing a maximal average power of $15 \mathrm{~W}$ at a wavelength of $1064 \mathrm{~nm}$. The pulse duration of the system was $70 \mathrm{ps}$, with a maximal pulse energy of $600 \mu \mathrm{J}$ at $1 \mathrm{kHz}$ repetition rate. Using a DLIP optics (Fraunhofer IWS, Dresden, Germany), two individual laser beams were overlapped at the stainless-steel surface (Figure 1a). Using this configuration, a characteristic line-like interference pattern is obtained, whose distance $p$ between the interference maxima (or minima) positions is controlled by the laser wavelength $\lambda$ and the angle between the laser beams $2 \theta$ (see Figure 1a), according to Equation (1):

$$
p=\frac{\lambda}{2 \sin (\theta)}
$$

By automatically varying the interference angle $\theta$ between $15.5^{\circ}$ and $5.5^{\circ}$ for the utilized wavelength, line-like structures with spatial periods between 2.0 to $5.5 \mu \mathrm{m}$ can be produced, respectively. The used structuring strategy for pulsed laser sources in a DLIP set-up consists on positioning the laser spot with the interference pattern on the sample and separate them a certain distance (vertical and lateral) in order to treat larger areas, which can be exemplarily seen in Figure 1b. Moving the sample with constant speed in one direction by a translation stage, indicated by the black arrow in Figure $1 b$, and irradiating with a fixed pulse repetition rate results in the treatment of a large area containing the interference structures. Following this direction, the constant distances between each pulse can also be described by the pulse-to-pulse overlap $(\mathrm{Ov})$ which can be calculated as function of the pulse distances and the spot-diameter (D). Accordingly, a value of zero overlap refers to a distance equal to the spot-diameter. The hatch $(\mathrm{H})$ value represents the same percentage relationship but in the direction 
perpendicular to the primary process direction (Figure 1b). In order to avoid damaging of the periodic structure previously produced, the hatch distance must be always equal to a multiple of the spatial period (p). The geometric layout for negative and positive Overlap and Hatch values $(-25 \%$ and $+25 \%$, respectively) are shown exemplary in Figure $1 b$.
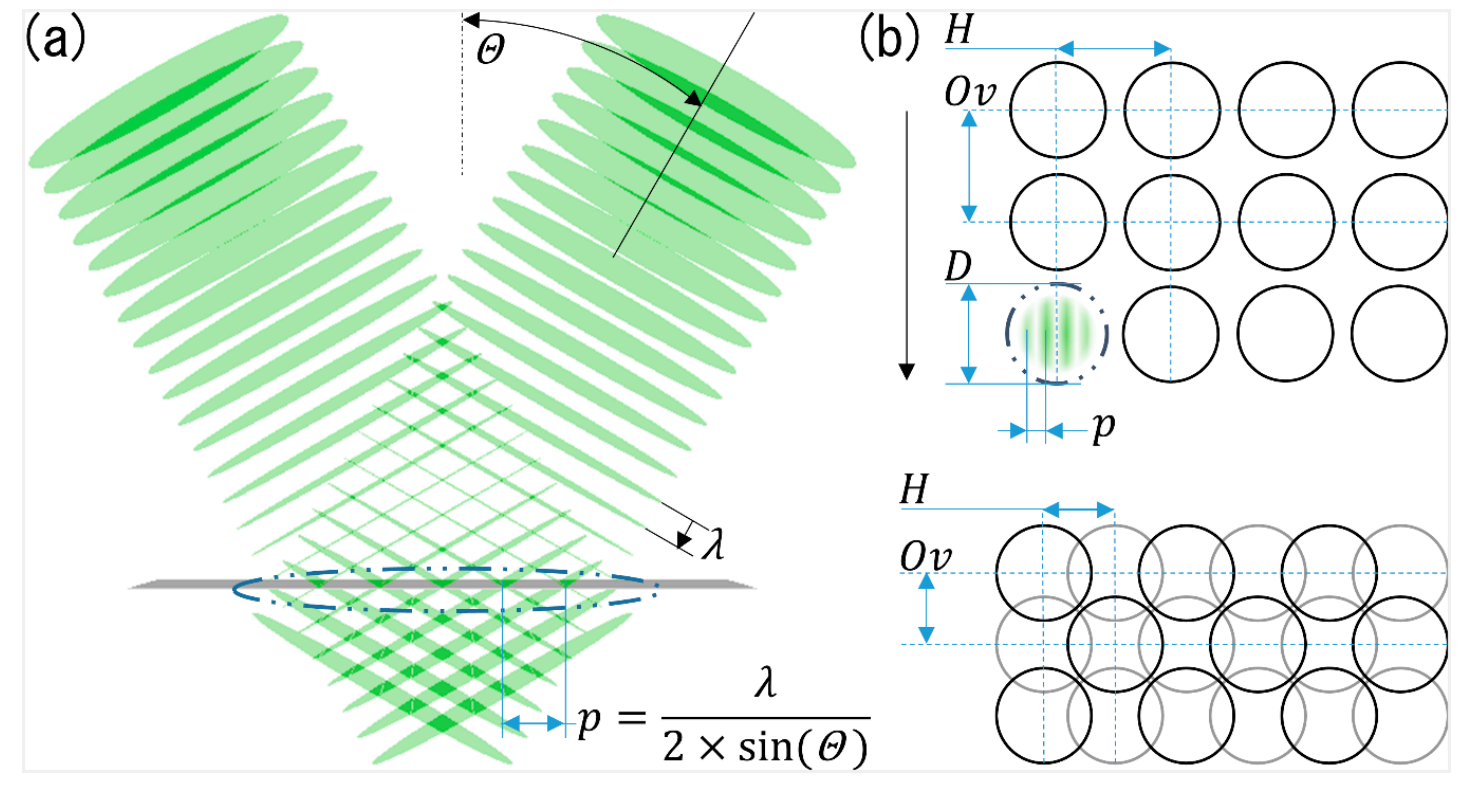

Figure 1. (a) Schematic representation of the two-beam DLIP principle for an overlap angle of $2 \Theta$ and a laser wavelength $\lambda ;(\mathbf{b})$ representation of the strategy used for processing the samples with: $\mathrm{D}=$ spot-diameter; $\mathrm{p}=$ spatial period; $\mathrm{Ov}=$ pulse to pulse overlap; $\mathrm{H}=$ hatch overlap. The upper image represents negatives $\mathrm{H}$ and $\mathrm{Ov}$ overlaps $(-25 \%)$, while in the lower image, the spots are overlapped by $+25 \%$ in both directions.

The surface topography of the structured samples was measured utilizing both non-contact confocal microscopy and white light interferometry methods (Sensofar S Neox 3D Surface Profiler, Barcelona, Spain).

\section{Results and Discussion}

\subsection{Development of an Optical Measurement System for Periodic Surface Structures}

It is well known, that when a periodic structure is irradiated with a coherent light source, a diffraction pattern is obtained. The reflected rays can be classified as diffraction orders, whereby the reflection angle $\Phi_{m}$ is proportional to the order number $m$, the wavelength $\lambda$ and the inverse of the spatial period $p$, as can be seen from the grating equation (Equation (2)):

$$
p \sin \phi_{m}=m \lambda
$$

for incident irradiation normal to the surface. Therefore, with increasing spatial period, the distance between the diffraction orders decreases when they are projected on a plane. In addition, the orientation in which the diffraction orders are deviated is also aligned to the periodic occurrence of the pattern. Moreover, patterns containing more than one repetitive length scale (as in the case of hierarchical structures) result on multiple diffractions orders based on the different modulations [39]. It is then possible to characterize the surface topography by collecting the diffraction orders with an imaging system. Next, the developed optical system capable of recording the patterns is described.

The schematic representation of the fabricated system is shown in Figure 2a. As it can be seen, a coherent light source with a wavelength of $532 \mathrm{~nm}$ is utilized to illuminate the textured surface, which 
is indicated in the image as the sample (S). To capture as many diffraction orders (DO) as possible and, in particular, to allow the analysis of patterns with short spatial periods (and thus high diffraction angles), a lens with a high numerical aperture is utilized (L2). For collimating the light reaching the sample surface, the Lens L1 is placed between the laser source and the lens L2. Further, two polarizers (P1 and P2) are used to control the illumination intensity (P1) as well as the reflected intensity (P2) which is guided to the camera (CAM). In this way, the illumination intensity can be adjusted during the experiments. A mirror (M) in combination with a polarized beam splitter (BS) and a quarter-wave plate (WP) are utilized to achieve a separation of the illumination source from the reflected radiation (containing the information about the surface topography) and using an imaging system consisting of two lenses (L3, L4), the reflected light can be collected by the camera.
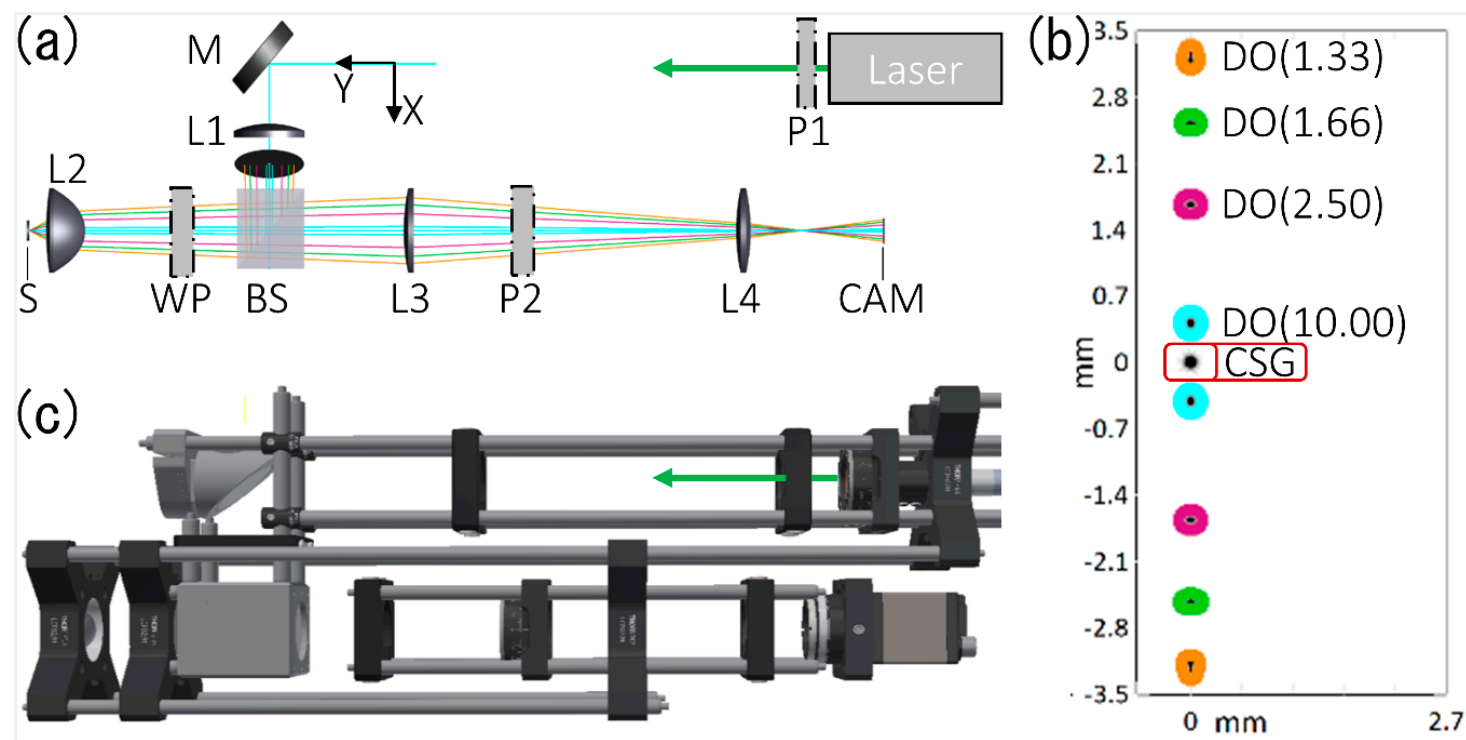

Figure 2. (a) Schematic optical set-up of the diffraction measurement system (M, mirror; $\mathrm{P}$, linear polarizer; L, lens; BS, beam splitter; WP, $\lambda / 4$ wave plate; CAM, Camera) including simulated rays diffracted by gratings with different periods (cyan, pink, green and orange lines); (b) Simulated sensor image at the camera (CAM) of the first diffraction orders (DO) for periods of 1.33, 1.66, 2.50 and $10.00 \mu \mathrm{m}$; CSG represents the Central Spot Group equivalent to the zero diffraction order; (c) CAD model of the fabricated optical system.

Using a simulation software (OpticStudio, Zemax LLC, Kirkland, WA, USA) in non-linear mode, all positions for the required optical components were calculated which are listed in Table 1. The simulation results suggest that with the designed measuring setup, the first diffraction orders corresponding to periods as low as $1.33 \mu \mathrm{m}$ (at an illumination wavelength of $532 \mathrm{~nm}$ ) can be recorded. As an example, the simulated positions for the first diffraction orders over the CCD camera sensor (CAM) for periods of $1.33 \mu \mathrm{m}, 1.66 \mu \mathrm{m}, 2.50 \mu \mathrm{m}$ and $10.00 \mu \mathrm{m}$ are indicated (see Figure 2b). The zero-order (normal to the surface, as the incident radiation) corresponds to the specular reflection and the image area around is defined for the rest of this work as Central Spot Group (CSG). For the mentioned periods in the simulation, the distances of the first-order diffractions to the center of the CCD are $0.5 \mathrm{~mm}, 1.7 \mathrm{~mm}, 2.5 \mathrm{~mm}$ and $3.1 \mathrm{~mm}$, respectively.

Finally, the measurement system was designed and constructed following the guidelines obtained from the optical simulation and using the components listed in Table 1, as shown in Figure 2c. As it can be seen, the laser source (laser diode CPS532-C2, Thorlabs Inc., Newton, NJ, USA, 532 nm, 0.9 mW) was integrated in the set-up. The polarizers are placed in rotational optic mounts to adjust the illumination and imaging intensity. For further adjustment to real environment, the optic mounts were placed on a cage system with freedom to move separately or in combination of groups. 
Table 1. Parameters and positions ( $\mathrm{X}$ and $\mathrm{Y}$ as indicated Figure 2a) of the different elements utilized for the optical imaging system simulation.

\begin{tabular}{|c|c|c|c|c|}
\hline ID & Object & $X(\mathrm{~mm})$ & $\mathrm{Y}(\mathrm{mm})$ & Parameter \\
\hline Laser & Coherent light source & 0 & 0 & $\lambda=532 \mathrm{~nm}, 0.9 \mathrm{~mW}, 3.5 \mathrm{~mm}$ beam diameter \\
\hline P1 & Polarizer & (0) & - & Linear Dichroic, $\lambda=400-700 \mathrm{~nm}$ \\
\hline $\mathrm{M}$ & Coupling Mirror & 0 & 60 & For $532 \mathrm{~nm}$ wavelength \\
\hline L1 & Lens & 20 & 60 & Plano-Convex, $\mathrm{N}-\mathrm{BK} 7, \mathrm{f}=75 \mathrm{~mm}$ \\
\hline BS & Beam Splitter & 49 & 60 & Polarized for $\lambda=532 \mathrm{~nm}$ \\
\hline WP & $\lambda / 4$ Wave plate & (49) & - & Zero order for $532 \mathrm{~nm}$ \\
\hline L2 & Lens & 49 & 140 & Asphere, N-BK7, $\mathrm{f}=16 \mathrm{~mm}, \mathrm{NA}=0.79$ \\
\hline $\mathrm{S}$ & Sample & 49 & 146 & Textured sample with different spatial periods \\
\hline L3 & Lens & 49 & -10 & Plano-Convex, N-BK7, f = $100 \mathrm{~mm}$ \\
\hline P2 & Polarizer & (49) & - & Linear Dichroic, $\lambda=400-700 \mathrm{~nm}$ \\
\hline L4 & Lens & 49 & -110 & Bi-Convex, N-BK7, f = $50 \mathrm{~mm}$ \\
\hline CAM & Camera & 49 & -160 & Camera screen size: $2.7 \mathrm{~mm} \times 3.4 \mathrm{~mm}$ \\
\hline
\end{tabular}

\subsection{Direct Laser Interference Patterning of Steel Surface}

Firstly, the electro-polished stainless-steel surface was treated using a constant laser fluence of $1.22 \mathrm{~J} / \mathrm{cm}^{2}$, varying both hatch-distance $(\mathrm{H})$ and pulse overlap (Ov). For instance, an overlap of $0 \%$ means that the separation between the laser pulses was $100 \mu \mathrm{m}$, corresponding to the utilized beam diameter (Gaussian shaped). The same criterion was used to describe the hatch-distance in $\%$. The interference spatial period was set to $4.9 \mu \mathrm{m}$ to decrease uncertainty about possible spherical aberration at small periods. The steel sample was structured in a matrix form with $12 \times 12$ fields, each with an area of $3 \mathrm{~mm}$ by $3 \mathrm{~mm}$, as can be seen in Figure 3a. Overlap (vertical, Y) and Hatch (horizontal, X) was varied from $0 \%$ to $99 \%$, respectively (stepwise $0 \%$ till $90 \%$ in $10 \%$ steps and then in addition with $95 \%$ and $99 \%$ ). The shiny colors for some laser processing parameters can be explained by the produced DLIP periodic structures as well as the occurrence of laser induced periodic surface structures (identified in scanning electron microscopy, not shown), which produce a characteristic rainbow color $[40,41]$. The darker areas in the textured samples correspond to high overlaps, which normally yield deep structures that reduce dramatically the surface reflectance.

Figure $3 b-d$ shows representative images of the surface topography of the laser treated samples, with a fixed spatial period of $4.9 \mu \mathrm{m}$, when using different hatch distances and overlaps. For instance, for $\mathrm{H}=0 \%$ and $\mathrm{Ov}=0 \%$, the DLIP spots are clearly separated (Figure $2 \mathrm{~b}$ ), being possible to easily distinguish them. Differently, when the hatch distance is reduced (e.g., $\mathrm{H}=99 \%$ ), keeping the overlap at $0 \%$, a wide area (which is determined by the laser spot diameter of $100 \mu \mathrm{m}$ ) containing the DLIP structures over the whole hatch direction was obtained as shown in Figure 3c. If both, the hatch and overlap distances are decreased, a more homogenous surface pattern is observed, where only the DLIP structures over the whole area are visible, as shown in Figure 3d. In addition to the topography of the produced patterns shown in Figure 3, also the corresponding diffraction images are indicated, which were captured with the CCD camera of the designed optical system. As stated, the distance between the different diffraction orders depends on the distance of the repetitive structures. Thus, the observed diffraction orders $(\mathrm{m}=-2, \mathrm{~m}=-1, \mathrm{~m}=0, \mathrm{~m}=1$ and $\mathrm{m}=2$ as indicated in Figure $3 \mathrm{c}$ ) correspond to the DLIP structures, while the additional features observed (exemplary the vertical distributed intensity peaks for $\mathrm{m}=0$ in Figure 3c) correspond to the larger repetitive patterns, which in turn correlate with both the used hatch and overlap distances. Additional information regarding the complex diffraction patterns observed can be found in [42,43]. 

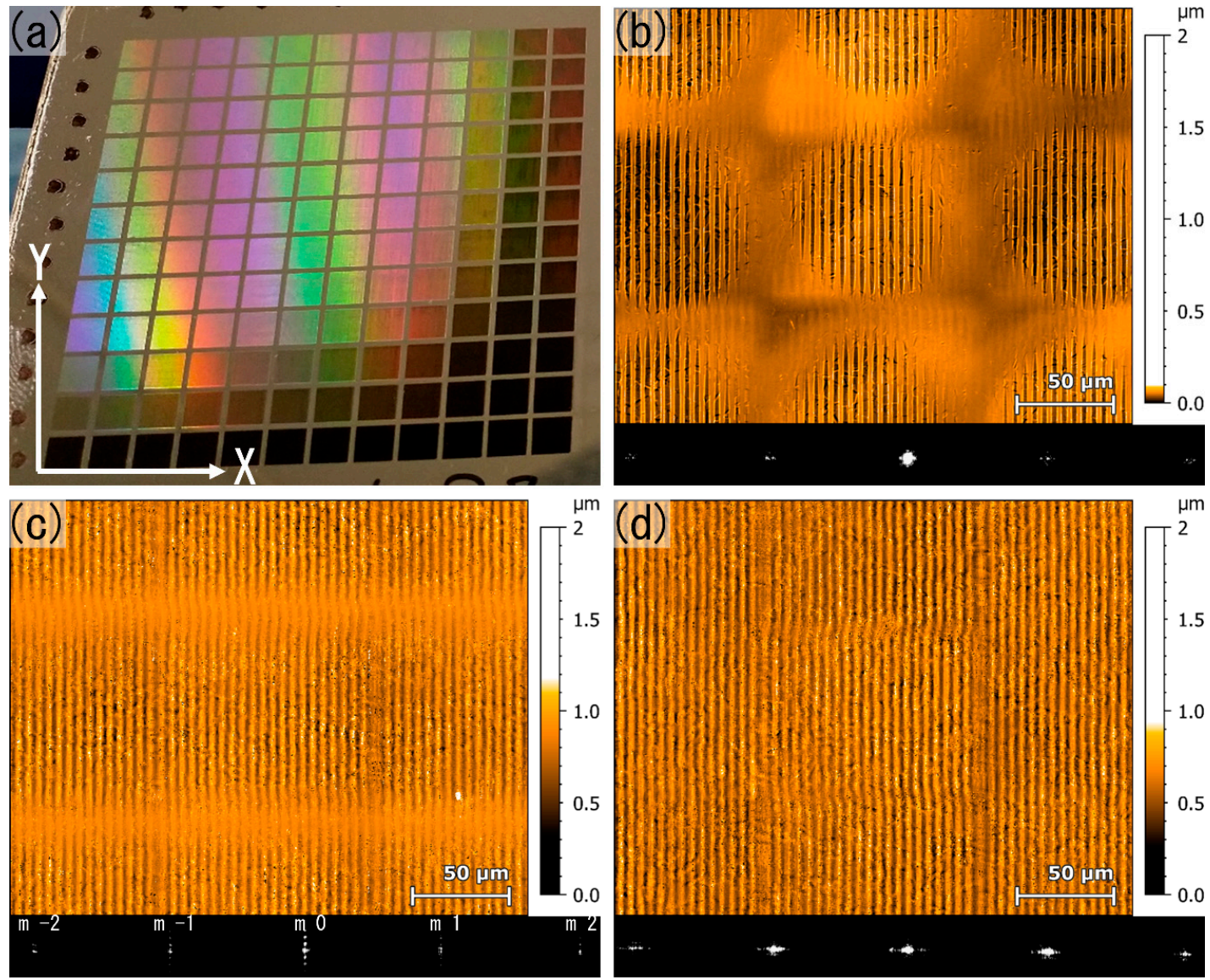

Figure 3. (a) DLIP structured stainless-steel sample with a matrix of $12 \times 12$ fields. The used laser fluence was $1.2 \mathrm{~J} / \mathrm{cm}^{2}$ and the hatch (horizontal) and pulse to pulse overlap (vertical) were varied in the range from $0 \%$ to $99 \%$ (with $10 \%$ steps till $90 \%$, and then $95 \%$ and $99 \%$ ); (b-d) Confocal microscopy images for (b) $\mathrm{Ov}=0 \%: \mathrm{H}=0 \%$, (c) $\mathrm{Ov}=0 \%: \mathrm{H}=99 \%$, (d) $\mathrm{Ov}=60 \%: \mathrm{H}=60 \%$. The insets show the recorded diffraction patterns by the CCD camera with $\mathrm{m}=-2, \mathrm{~m}=-1, \mathrm{~m}=0, \mathrm{~m}=1$ and $\mathrm{m}=2$ (in (c)) as indicators for the diffraction orders accountable from the DLIP structures.

In order to quantitatively characterize the homogeneity of the different periodic structures as function of the used hatch distances and overlaps, both the mean structure depth of the periodic structures, corresponding to the interference pattern (called from now on "first modulation", $\mathrm{Z}_{\mathrm{fm}}$ ) as well as the structure height of the larger surface structure (denoted as "second modulation", $Z_{\mathrm{sm}}$ ) were determined. These values are plotted for the second modulation in Figure $4 \mathrm{a}, \mathrm{b}$ and for the first modulation in Figure 4c. As it can be seen from Figure 4c, the height of the DLIP structures increases with higher overlap and hatch. This can be explained by the number of pulses that are irradiating the same area and therefore the contributed sum of pulse energy (exposure dose or accumulated fluence) facilitating the ablation process, which was already demonstrated elsewhere [44]. For instance, an overlap and hatch of $0 \%$ to $80 \%$ means an increase from 1 to 16 pulses, while overlap and hatch from $80 \%$ to $99 \%$ results in 25 to 100 pulses. Figure $4 \mathrm{c}$ also shows, that in these experiments, mean structure depths from $\sim 100 \mathrm{~nm}$ to $\sim 5 \mu \mathrm{m}$ could be achieved.

The height of the second modulation $\left(Z_{\mathrm{sm}}\right)$ was measured along to either the orientation according to the $X$ (Figure $4 a$ ) or $\mathrm{Y}$ (Figure $4 \mathrm{~b}$ ) coordinates as indicated in Figure 3a. Taking into account that the interference pattern is created within a Gaussian beam distribution, it can be expected that more pulses (high overlaps) impinging the material surface can produce deeper valleys [45]. Thus, when the hatch percentage is increased above $70 \%$ at constant overlap values, deeper valleys oriented unidirectional along the $X$-axis (see Figure $3 c$ ) are produced, resulting in a significant increase of the second modulation depth $Z_{\mathrm{sm}}(\mathrm{Y})$ measured perpendicular to the valley orientation as shown in 
Figure $4 \mathrm{~b}$. The same effects occur when increasing the overlap percentage at constant hatch distances. Thus, in this case the second modulation depth measured along $X Z_{\mathrm{sm}}(X)$ (Figure 4a) increases, as the valleys are oriented perpendicular again. In comparison, $Z_{\mathrm{sm}}(X)$ reaches a minimum of $2 \mu \mathrm{m}$ at $99 \%$ overlap, while $Z_{\mathrm{sm}}(\mathrm{Y})$ only reaches a minimum of $0.7 \mu \mathrm{m}$ at $99 \%$ Hatch. This can be explained by the hatch distance correction, necessary to avoid destroying the line-like DLIP structures as explained in Section 2 and the resulting total energy input to the surface. An assigned hatch $\mathrm{H}$ from $95 \%$ and $99 \%$ corresponds to an actual hatch distance of $9.8 \mu \mathrm{m}$ (two times the spatial period of $4.9 \mu \mathrm{m}$ ) and $4.9 \mu \mathrm{m}$ (equal to spatial period), respectively, whereas for the same overlap Ov percentages of $95 \%$ and $99 \%$ the corresponding spot-to-spot distance observed on the structured sample is $5 \mu \mathrm{m}$ and $1 \mu \mathrm{m}$, respectively. For overlaps and hatches below $85 \%$ (corresponding to less than 45 pulses), the second modulation depth in either direction is below $500 \mathrm{~nm}$.
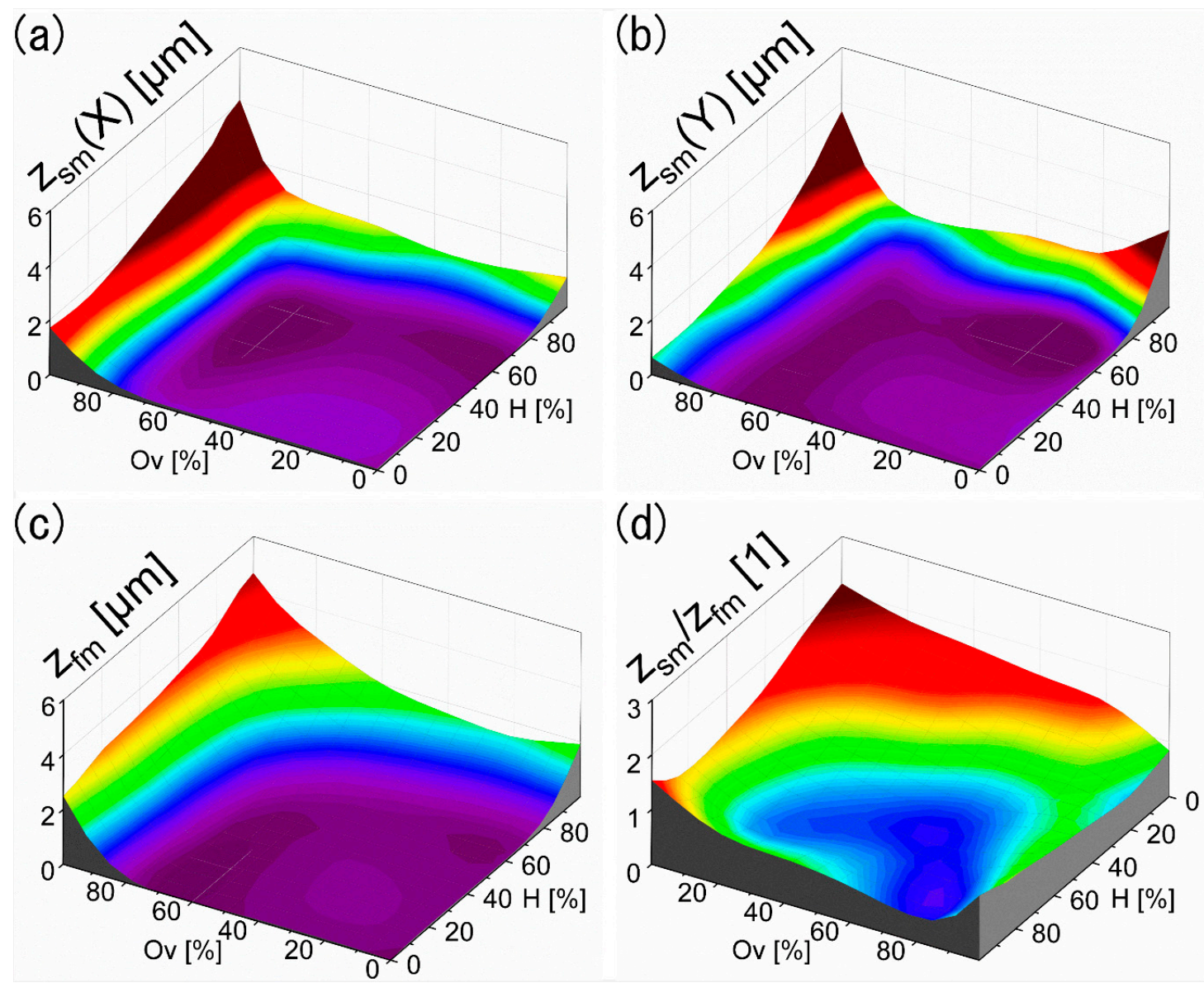

Figure 4. Topographical measurements of structure depths $(\mathrm{z})$ as function of overlap and hatch values. (a) Second modulation depth measured along $X$-orientation $Z_{\mathrm{sm}}(\mathrm{X})$ and (b) Y-orientation $\mathrm{Z}_{\mathrm{sm}}(\mathrm{Y})$; (c) mean DLIP structure depth $Z_{\mathrm{fm}} ;(\mathbf{d})$ quotient between both depth modulations $\left(Z_{\mathrm{sm}} / \mathrm{Z}_{\mathrm{fm}}\right.$ defined in Equation (3)).

Since a homogenous DLIP structure can be characterized by having large depths for the periodic structure $\left(Z_{\mathrm{fm}}\right)$ as well as simultaneously low depths for the large pattern modulation $\left(Z_{\mathrm{sm}}\right)$, the ratio between both parameters $\left(Z_{\mathrm{sm}} / \mathrm{Z}_{\mathrm{fm}}\right)$ was calculated using Equation (3):

$$
\frac{Z_{s m}}{Z_{f m}}=\frac{\sqrt{\left(Z_{s m}(X)^{2}+Z_{s m}(Y)^{2}\right)}}{Z_{f m}}
$$


This ratio is shown as function of both hatch and overlap percentages in Figure $4 \mathrm{~d}$. Note that the lateral scales, i.e., $\mathrm{Ov}$ and $\mathrm{H}$, were flipped for a better visualization. Using this criterion, the samples with low $Z_{\mathrm{sm}} / Z_{\mathrm{fm}}$ ratio correspond to textures where the periodic structure produced by the interference pattern is dominant (see for instance Figure 3d). As it can be seen in Figure $4 d$, laser textured surfaces with overlap and hatch values below $20 \%$ are highly inhomogeneous as the second modulation is more dominant compared to the DLIP structure modulation. For overlaps ranging from $40 \%$ to $85 \%$ as well as hatches between $40 \%$ and $85 \%$, the lowest $Z_{\mathrm{sm}} / Z_{\mathrm{fm}}$ ratios were obtained (down to $\sim 0.3$ ). For overlaps and hatches above $85 \%$ the structure becomes inhomogeneous due to the high applied energy leading to a significant deterioration of the pattern uniformity as discussed elsewhere [46].

\subsection{Characterization of the Laser Textured Surfaces Using the Developed Optical Module}

After determining the topographical parameters of the different treated samples as function of hatch distance and overlap, the developed monitoring device was evaluated. The first aim was to determine if it is possible to define different parameters that can be correlated with the structure homogeneity, defined in this work as $Z_{\mathrm{sm}} / \mathrm{Z}_{\mathrm{fm}}$,

With the whole diffraction pattern recorded for each sample, we first calculated the average pixel distance between the zero order to the minus and plus first diffraction orders corresponding to the first modulation (exemplarily $\mathrm{m}=-1, \mathrm{~m}=0$ and $\mathrm{m}=1$ in Figure $3 \mathrm{c}$ ), to monitor the periodicity of the manufactured structures. Taking into account all the samples that showed enough intensity irradiating the CCD sensor from the reflected light (a discussion on this regard will be given below), the mean distance was 166.9 pix with a standard deviation of only 4.5 pix. Considering that the obtained standard deviation is only $2.7 \%$ of the calculated mean value, it can be stated that the period of the DLIP structure is stable over all the analyzed samples. The calculation was also migrated in the evaluation algorithms utilizing the dilated image of the CCD (visualized in the Supplementary Material S1 and S2), showing the same results. Considering the relationship between the diffraction order angle for a specific diffraction order $\mathrm{m}$ (see Equation (2)), as well as by performing a calibration of the system with known periodic patterns, the mean distance between the first order and the zero order of 166.9 pix was found to represent a spatial period of $4.905 \mu \mathrm{m}$. Using this information, it was possible to calculate the spatial period of the repetitive pattern as function of the overlap and hatch values as shown in Figure 5. As it can be seen, the detected period oscillated slightly around its mean value and its variation corresponds to a standard deviation of $0.15 \mu \mathrm{m}$ with two outliers of $4.76 \mu \mathrm{m}$ (overlap of $20 \%$ and hatch of $99 \%$ ) and $5.78 \mu \mathrm{m}$ (overlap of $40 \%$ and hatch of $0 \%$ ). For samples where no diffraction image on the sensor could be captured, no periods can be calculated and, therefore, no values are present in Figure 5.

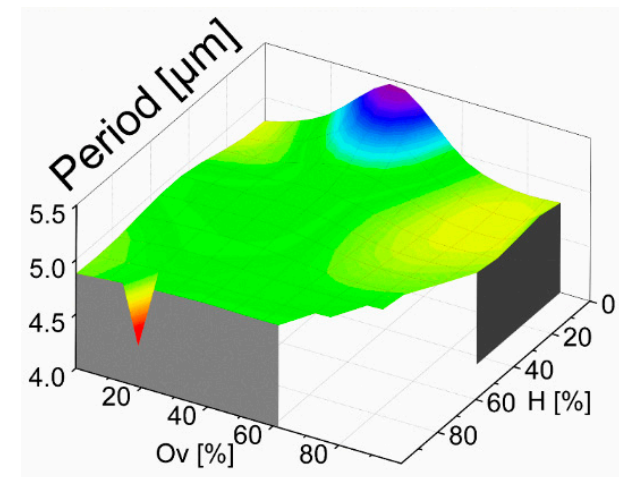

Figure 5. Representation of the spatial period as function of hatch and overlap calculated after calibration of the optical device.

For further evaluation, we decided as a first approach to analyze only the central spot group (CSG). The reason for this is that in preliminary experiments (not shown) the direct reflected zero-order 
showed the most promising, as in most sensitive and clearly distinguishable images to the naked eye for different modulations. Exemplary images of the CSGs recorded with the CCD camera are shown in Figure 6 for different DLIP processed stainless steel samples, grouped by constant overlap percentages of $0 \%, 40 \%, 80 \%$ and $95 \%$ (Ov-Groups) with hatch parameters of $0 \%, 40 \%, 80 \%$ and $99 \%$, respectively.
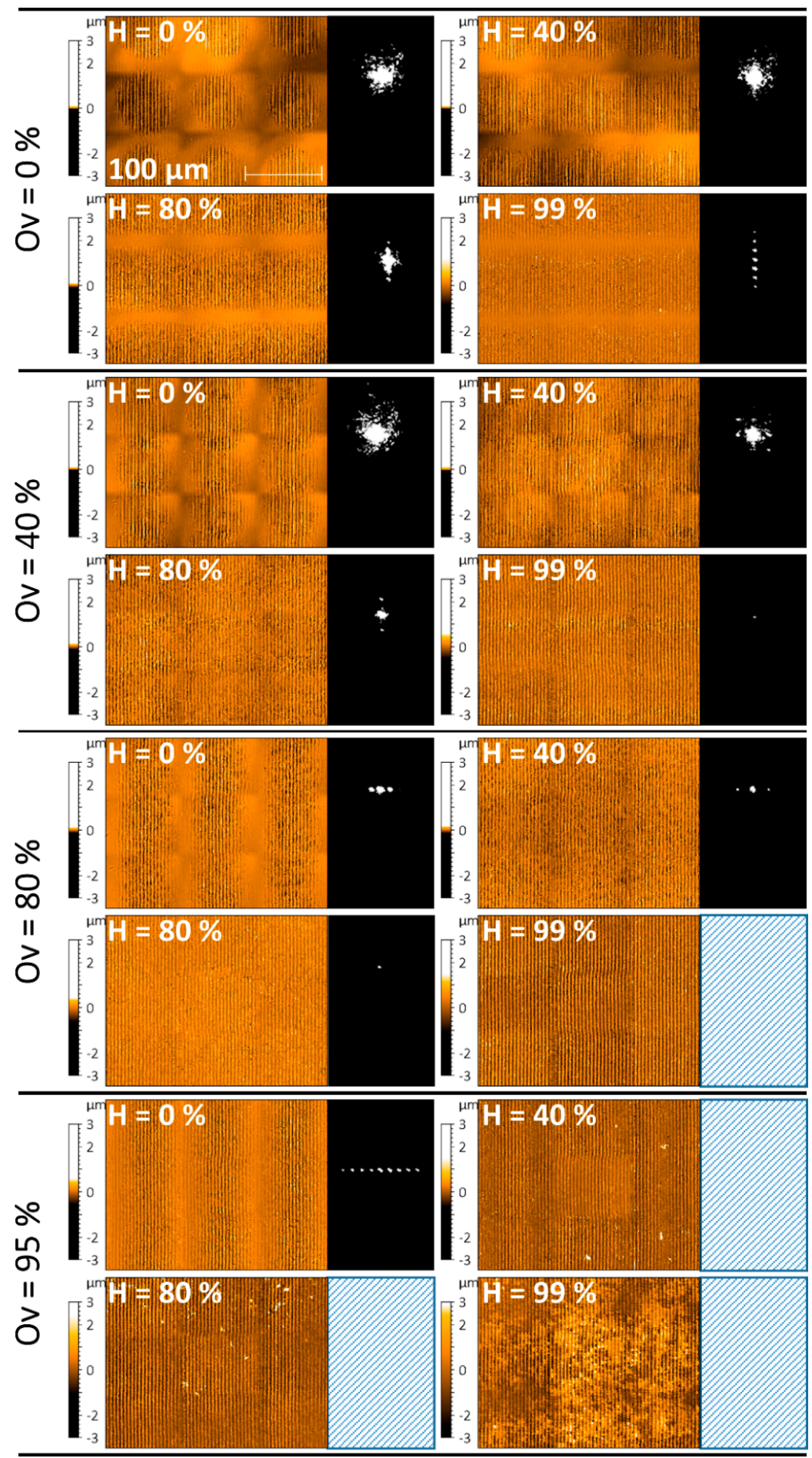

Figure 6. Exemplary selected confocal microscopy images (left) and captured diffraction pattern of the Central Spot Group (CSG) (right) as function of both overlap (Ov) and hatch (H). The blank rectangles indicate that no light intensity could be recorded. 
As it can be seen in Figure 6, for an overlap Ov $=0 \%$ (see top images), an increase in the hatch overlap percentage results in an elongated central spot group in the direction parallel to the interference lines, or perpendicular to the large modulation pattern. This can be attributed to the superposition of several laser pulses in the hatch direction. Moreover, it can be clearly seen that for a hatch $\mathrm{H}$ of $99 \%$, the CSG shows several spots perpendicular to the hatch direction, since the repetitive large modulation also diffracts the incoming light into well-defined directions. A similar behavior is observed when keeping the hatch overlap $\mathrm{H}$ at $0 \%$ and increasing the pulse overlap, which can be seen following the upper left images of the Ov-Groups in Figure 6. Since in this situation the second modulation periodicity is dependent on the hatch distance and, therefore, the macrostructure valley orientation is parallel to the DLIP structures, the elongation of the CSG as well as the splitting occurs in the same direction as the diffraction from the DLIP structures. Moreover, the splitting direction occurs in respect to the dominant repetitive orientation of the second modulation; as for overlaps Ov of $40 \%$ and hatch $\mathrm{H}$ of $80 \%$, the diffraction orders split vertically, but upon inverting the parameters $(\mathrm{Ov}=80 \%$ and $\mathrm{H}=40 \%$ ), the diffraction orders split horizontally. For certain $\mathrm{Ov}$ and $\mathrm{H}$ values in the range of $20 \%$ to $60 \%$, for instance, $\mathrm{Ov}=40 \%$ and $\mathrm{H}=40 \%$, both splitting directions can be distinguished in a sort of a two-dimensional split diffraction of the CSG. It is worth to mention that on surfaces showing a high homogeneity (such as for $\mathrm{Ov}$ and $\mathrm{H}=80 \%$ or Ov $=40 \%$ and $\mathrm{H}=99 \%$ ), the CSG is reduced to a very small spot, since the periodic structure corresponding to the interference patterns acts as a very well-defined diffraction grating.

Finally, in the cases of stainless steel surfaces which were processed at very large overlap and hatch percentages, the developed optical module was not capable of collecting sufficient light intensity since these samples presented a very dark appearance and thus their reflectivity is strongly reduced compared to the other samples (see Figure 3a, on the bottom/right corner).

Based on the preliminary information reported in the previous section, for indirectly evaluating the quality and morphology of the produced surface patterns, two figures of merit are defined: (i) the amount of diffraction orders corresponding to the second modulation within the CSG (defined as Diffraction Order Count $\mathrm{DOC}_{\mathrm{sm}}$ ) and (ii) the total area of the central spot group (CSG) recorded by the camera sensor $\left(\mathrm{A}_{\mathrm{CSG}}\right.$ ). The developed algorithms used for the calculation of both $\mathrm{DOC}_{\mathrm{sm}}$ and $\mathrm{A}_{\mathrm{CSG}}$, are based on OpenCv [47] image processing library and are presented in the supplementary information section. Figure 7 shows (a) the $\mathrm{DOC}_{\mathrm{sm}}$ and (b) $\mathrm{A}_{\mathrm{CSG}}$ parameters, as function of the overlap Ov and hatch $\mathrm{H}$. As it can be seen in Figure 7a, the amount of diffraction orders emitted by the second modulation increases with reduced $\mathrm{Ov}$ and $\mathrm{H}$ values. For example, $\mathrm{DOC}_{\mathrm{sm}}$ reaches values up to $\sim 20$ orders for overlaps and hatches smaller than $40 \%$. Recalling the topographies in Figure 6 with Ov and $\mathrm{H}$ below $40 \%$, it is possible to see that significant areas of those samples remain unstructured, and thus, the reflected light (from the illumination system) is mostly directed to the CCD sensor or scattered, leading to a broad central spot surrounded by several smaller spots. In this case, the $\mathrm{DOC}_{\mathrm{sm}}$ calculation includes the total amount of every separated illumination area detected on the sensor rather than the actual diffraction orders caused by the second modulation. With increasing hatch $\mathrm{H}$ and overlap Ov, the structures become deeper (see Figure 4) and the reflected light splits into better defined diffraction orders. For instance, the CSG shows only about 3 individual spots when using $\mathrm{H} \sim 20 \%$ and Ov $\sim 60 \%$, as well as for $\mathrm{H} \sim 95 \%$ and $\mathrm{Ov} \sim 20 \%$.

As observed in Figure $7 \mathrm{~b}$, the area of the CSG $\mathrm{A}_{\mathrm{CSG}}$ is comparatively large for overlap and hatch values below $40 \%$, due to the same reasons mentioned above for the $\mathrm{DOC}_{\mathrm{sm}}$ values. As the overlap or hatch values increase, more distinct diffraction spots are recorded causing a reduction of the $\mathrm{A}_{\mathrm{CSG}}$ parameter. For the most homogeneous structures showing only the DLIP features, the CSG consists only of a single spot with a small area, as explained before. In consequence, small $\mathrm{A}_{\mathrm{CSG}}$ as well as a $D C_{\mathrm{sm}}=1$ are expected. This case was observed in those samples with overlaps Ov and hatch $\mathrm{H}$ combinations in the range of $60 \%$ to $95 \%$ each. 
(a)

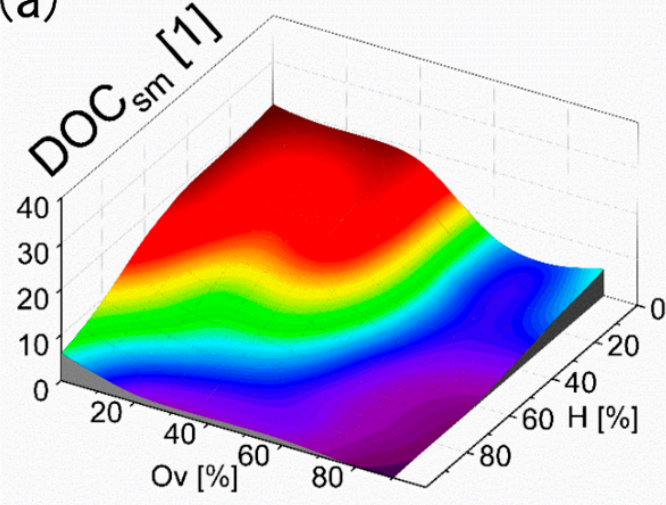

(b)

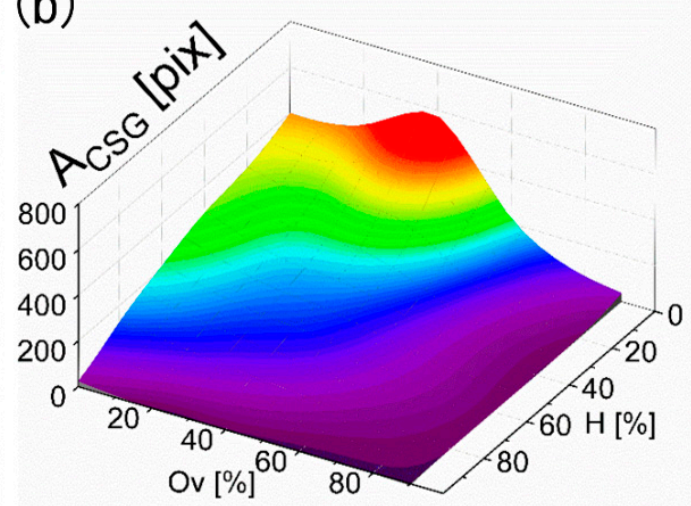

Figure 7. (a) Measured diffraction order count of the second modulation $\left(\mathrm{DOC}_{\mathrm{sm}}\right)$ and (b) total area illuminated of the Central Spot Group ( $\mathrm{A}_{\mathrm{CSG}}$ ) plotted over overlap and hatch values.

Finally, the measured parameters describing the real surface topography of the different produced patterns from Section 3.1 are compared with the parameters of the diffractive approach. The main objective is to determine the possibility of using the information recorded by the developed optical module for describing the real topography. As it can be seen in Figure 8, the monitoring parameters $\left(D_{\mathrm{sm}}\right.$ in Figure 8a and $\mathrm{A}_{\mathrm{CSG}}$ in Figure $8 \mathrm{~b}$ ) were plotted against the homogeneity coefficient $\left(Z_{\mathrm{sm}} / \mathrm{Z}_{\mathrm{fm}}\right.$ in Figure $\left.4 \mathrm{~d}\right)$. For a better understanding of the type of topography representing each experimental data point, the data was categorized as listed in Table 2 and also displayed according to their category with different colors and symbol shapes, depending on the categories defined.

As the goal of the diffractive approach is differentiating between homogenous and inhomogeneous structures, the homogeneity quotient $Z_{\mathrm{sm}} / Z_{\mathrm{fm}}$ boundary was arbitrarily defined as 0.7 , resulting in categories \#1 to \#4 for good homogeneity (below 0.7 ) and categories \#5 to \#8 for poor homogeneity (above 0.7 ). To draw a conclusion, if the developed system can distinguish the homogeneity by the diffraction analysis parameters, each category range is further subdivided in small and large A $_{\text {CSG }}$ (separation limit of 100 pix), as well as in few and many DOC $_{\mathrm{sm}}$ (separation limit of 2) according to Table 2. Category \#10 is introduced for those samples whose diffraction data could not be obtained due to no measurable intensity of reflected light. Category \#7 (and also \#3) would probably per definition point towards a mirror-like surface with no scattering, which was not recorded by the developed system nor topographically measured at all and, therefore, will not be discussed further. Samples featuring homogeneous structures would be, by the definitions made and relations shown, expected to only show up in category \#1 with no splitting due to the second modulation ( $\mathrm{DOC}_{\mathrm{sm}} \leq 2$ in Figure $8 \mathrm{a}$ ) and small illumination area $A_{C S G}(<100$ pix in Figure $8 b)$. This is in agreement with textured samples previously discussed for overlap and hatch parameters of $60 \%$ to $85 \%$, shown in Figure 8 c. However, there is a mismatch for samples with slightly varied structuring parameters as seen in Figure $8 \mathrm{c}$ (category \#5), which suggest a good homogeneity (small illuminated area $\mathrm{A}_{\mathrm{CSG}}$ and $\mathrm{DOC}_{\mathrm{sm}}$ of 1 or 2), while actually being inhomogeneous by topographically measurements $\left(Z_{\mathrm{sm}} / Z_{\mathrm{fm}}>0.7\right)$. For these samples, the reflected diffraction pattern has a low intensity which cannot give enough contrast on the CCD sensor, making the additional splitting orders not detectable. This can be also concluded by looking to the illuminated area which for these samples is close to zero ( $\mathrm{A}_{\mathrm{CSG}}<4$ pix). Further strengthening this reasoning, the samples classified as \#5 type are occurring close to category \#6 type samples in terms of their structuring parameters (as seen in Figure 8c). As stated before, a high number of the $\mathrm{DOC}_{\mathrm{sm}}$ in combination with a small illuminated area can be attributed to splitting of the CSG and therefore to an inhomogeneous structure with a dominant second modulation, which corresponds very well with the samples in category \#6 (see Figure 8a).

Category \#2 cannot be distinguished from category \#6 by the developed system alone, as both would indicate a splitting behavior of the CSG (DOC values $>2$ ) and therefore a significant contribution 
from the second modulation to the diffraction pattern. For samples of category \#6 this is in agreement with the homogeneity factor $\left(Z_{\mathrm{sm}} / Z_{\mathrm{fm}}>0.7\right)$. Although, the topographical data of the samples in category \#2 imply a good homogeneity (homogeneity factor $\sim 0.5$ in Figure $4 \mathrm{~d}$ ), it can be observed that the developed system clearly detects the second modulation within the diffraction images (exemplary $\mathrm{Ov}=40 \%$ and $\mathrm{H}=80 \%$, as well as $\mathrm{Ov}=80 \%$ and $\mathrm{H}=40 \%$ in Figure 6 ).

Similarly, category \#4 and category \#8 would be measured by the optical system as inhomogeneous. In the case of category \#8, the reason can be attributed to high scattering and a large illumination area, which corresponds to an only partly structured surface. In turn, for category \#4 samples, this can be explained by a relatively shallow surface texture, where even a shallower second modulation (contributing to a low homogeneity factor) has a significant impact on the whole surface morphology and therefore on the diffraction image.

Table 2. Definition of categories \#1 to \#10 for treated samples by the homogeneity factor $Z_{\mathrm{sm}} / Z_{\mathrm{fm}}$, the illumination area of the CSG $A_{C G S}$ and the diffraction order count obtained from the second modulation $\mathrm{DOC}_{\mathrm{sm}}$. Note that no samples fitted in the categories \#3 and \#7.

\begin{tabular}{|c|c|c|c|c|c|c|c|c|c|}
\hline Category \# & 1 & 2 & 3 & 4 & 5 & 6 & 7 & 8 & 10 \\
\hline $\mathrm{Z}_{\mathrm{sm}} / \mathrm{Z}_{\mathrm{fm}}$ & \multicolumn{4}{|c|}{$<0.7$} & \multicolumn{4}{|c|}{$>0.7$} & No Data \\
\hline $\mathrm{A}_{\mathrm{CSG}}$ & \multicolumn{2}{|c|}{$<100$} & \multicolumn{2}{|c|}{$>100$} & \multicolumn{2}{|c|}{$<100$} & \multicolumn{2}{|c|}{$>100$} & \\
\hline $\mathrm{DOC}_{\mathrm{sm}}$ & $\leq 2$ & $>2$ & $\leq 2$ & $>2$ & $\leq 2$ & $>2$ & $\leq 2$ & $>2$ & \\
\hline $\begin{array}{c}\text { CSG example } \\
\text { in Figure } 6 \\
\text { Ov,H }\end{array}$ & 80,80 & 40,80 & - & 40,60 * & 40,99 & 0,99 & - & 40,0 & - \\
\hline
\end{tabular}

* can be found in supplementary Figure S3.

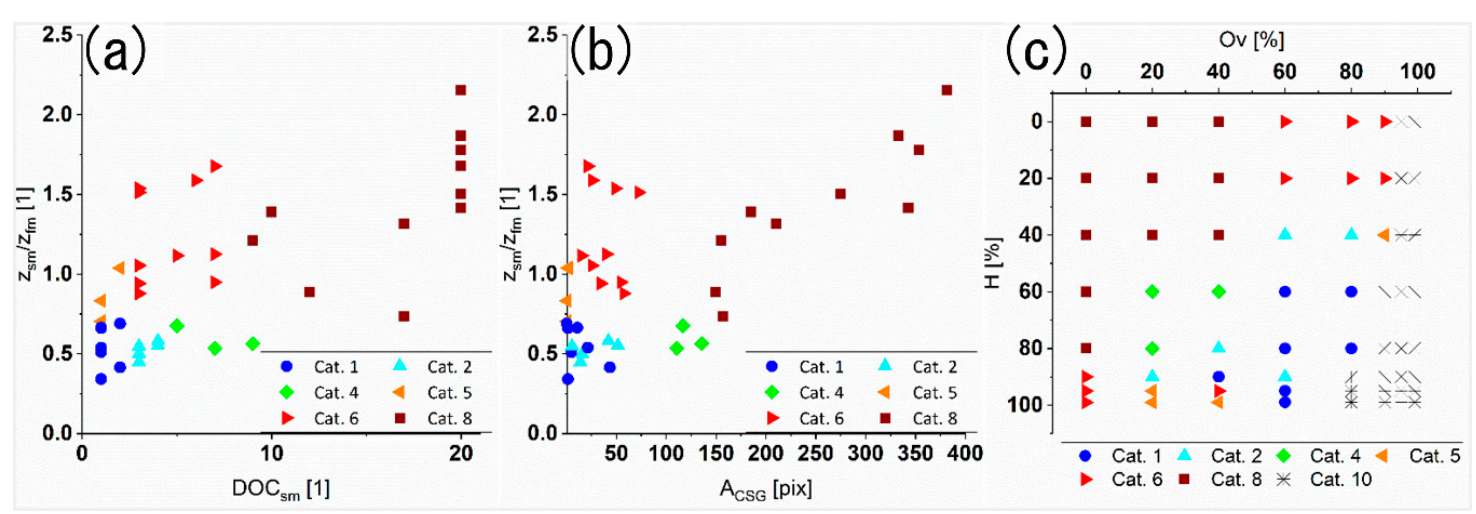

Figure 8. Categorized results of the homogeneity fraction $Z_{\mathrm{sm}} / Z_{\mathrm{fm}}$ (depth of first modulation by the DLIP structure to depth of the second modulation ratio) in comparison to (a) Diffraction Order Count of second modulation (DOC $\mathrm{sm}$ ) and (b) Area of the Central Spot Group (A $\left.\mathrm{A}_{\mathrm{CSG}}\right)$ ); (c) Representation of the different category-definitions as function of hatch $\mathrm{H}$ and overlap Ov. The different categories are listed in Table 2.

Possible solutions to enhance the monitoring device detection quality will be evaluated, including a more precise illumination control (to avoid saturation at the CCD camera) combined with a more powerful illumination source, as well as a camera with better dynamic range or fine tuning of the evaluation algorithms. In this work, the structured samples were directly evaluated by topographic criteria alike to other measurement systems like confocal microscopy. The oxidation on the surface or its degree and a possible impact on the measurements have not been considered or studied.

\section{Conclusions}

In this work, an optical approach was developed and constructed for the indirect evaluation of the quality and morphology of surface structures manufactured with DLIP. For testing the designed 
optical configuration, line-like surface patterns were produced on stainless steel with a periodicity of $4.9 \mu \mathrm{m}$ utilizing a two-beam DLIP configuration. Depending on the pulse to pulse overlap and hatch distance, it was possible to fabricate complex geometries presenting non-homogenous and homogenous surface patterns.

The developed optical system permitted us to successfully capture reflective features from the textured surfaces that were used for evaluation and monitoring purposes. Different algorithms were developed for processing the captured images, in order to calculate the periodicity of the first modulation, the total area of the central spot as well as the number of diffraction orders that correspond to the second modulation (if any) of the structure. By comparison to topographical measurements, it was shown that the developed approach was capable to distinguish between different structures groups, which were characterized by specific surface parameters. Moreover, in comparison to the topographical measurements and calculations, the system shows more precise detection of existing second modulations for shallow surface structures. However, the measurement quality of the system as for now was found to be limited by the illumination source (low power diode laser) and thus to not permit characterizing patterns with deep structures. Since periodic patterns exhibiting high homogeneity are relevant for many surface functions (for example for surfaces with enhanced optical properties), the presented method will be relevant in the future to monitor the manufacturing process, being capable to ensure high quality as well as to detect process instabilities and new hints to understand the underlying mechanisms by which the resulting textures are produced. These topics will be investigated in the future.

Supplementary Materials: The following are available online at http://www.mdpi.com/1996-1944/13/1/53/s1, Figure S1: Evaluation algorithm flow chart and algorithm declarations with examples, Figure S2: Subroutine algorithm of categorization flow chart, Figure S3: Example CSG of category \#4.

Author Contributions: Conceptualization, S.T.-W., B.V. and A.F.L.; methodology, S.T.-W. and B.V.; software, S.T.-W.; validation S.T.-W.; formal analysis, S.T.-W. and B.V.; investigation, S.T.-W.; resources, S.T.-W. and B.V.; data curation, S.T.-W.; Writing-Original draft preparation, S.T.-W. and A.F.L.; Writing-Review and editing, M.S. and A.F.L.; visualization, S.T.-W. and M.S.; supervision, A.F.L. All authors have read and agreed to the published version of the manuscript.

Funding: This work was carried out in the framework of the Reinhart-Koselleck project [323477257], which has received funding from the German Research Foundation (German: Deutsche Forschungsgemeinschaft DFG). The work of A.F.L. is also supported by the German Research Foundation (DFG) under Excellence Initiative program by the German federal and state government to promote top-level research at German universities.

Acknowledgments: Marcos Soldera acknowledges the support of the Alexander von Humboldt Foundation. Open Access Funding by the Publication Fund of the TU Dresden

Conflicts of Interest: The authors declare no conflict of interest.

\section{References}

1. Ensikat, H.J.; Ditsche-Kuru, P.; Neinhuis, C.; Barthlott, W. Superhydrophobicity in perfection: The outstanding properties of the lotus leaf. Beilstein J. Nanotechnol. 2011, 2, 152-161. [CrossRef] [PubMed]

2. Bhushan, B.; Jung, Y.C.; Koch, K. Micro-, nano- and hierarchical structures for superhydrophobicity, self-cleaning and low adhesion. Philos. Trans. R. Soc. A Math. Phys. Eng. Sci. 2009, 367, 1631-1672. [CrossRef] [PubMed]

3. Watson, G.S.; Green, D.W.; Schwarzkopf, L.; Li, X.; Cribb, B.W.; Myhra, S.; Watson, J.A. A gecko skin micro/nano structure-A low adhesion, superhydrophobic, anti-wetting, self-cleaning, biocompatible, antibacterial surface. Acta Biomater. 2015, 21, 109-122. [CrossRef] [PubMed]

4. Jwad, T.; Walker, M.; Dimov, S. Erasing and rewriting of titanium oxide colour marks using laser-induced reduction/oxidation. Appl. Surf. Sci. 2018, 458, 849-854. [CrossRef]

5. Li, G.; Li, J.; Hu, Y.; Zhang, C.; Li, X.; Chu, J.; Huang, W. Realization of diverse displays for multiple color patterns on metal surfaces. App. Surf. Sci. 2014, 316, 451-455. [CrossRef]

6. Bruening, S.; Du, K.; Jarczynski, M.; Jenke, G.; Gillner, A. Ultra-fast laser micro processing by multiple laser spots. Procedia CIRP 2018, 74, 573-580. [CrossRef]

7. Héquet, A.; Humblot, V.; Berjeaud, J.-M.; Pradier, C.-M. Optimized grafting of antimicrobial peptides on stainless steel surface and biofilm resistance tests. Colloids Surf. B Biointerfaces 2011, 84, 301-309. [CrossRef] 
8. Lutey, A.H.A.; Gemini, L.; Romoli, L.; Lazzini, G.; Fuso, F.; Faucon, M.; Kling, R. Towards Laser-Textured Antibacterial Surfaces. Sci. Rep. 2018, 8, 10112. [CrossRef]

9. Williams, T.L.; Rawlings, D.C. Aerodynamic microstructures having sub-microstructures. U.S. Patent US9868135B2, 16 January 2018.

10. Walsh, M.J.; Anders, J.B.; Hefner, J.N. Combined riblet and lebu drag reduction system. U.S. Patent 4706910A, 17 November 1987.

11. Wong, V.W.; Tung, S.C. Overview of automotive engine friction and reduction trends-Effects of surface, material, and lubricant-additive technologies. Friction 2016, 4, 1-28. [CrossRef]

12. Moebius, M.; Vora, K.; Kang, S.; Munoz, P.; Deng, G.; Mazur, E. Direct Laser Writing of 3D Gratings and Diffraction Optics. In Proceedings of the 2015 Conference on Lasers and Electro-Optics (CLEO), San Jose, CA, USA, 10-15 May 2015; p. SW1K.6.

13. England, G.; Kolle, M.; Kim, P.; Khan, M.; Munoz, P.; Mazur, E.; Aizenberg, J. Bioinspired micrograting arrays mimicking the reverse color diffraction elements evolved by the butterfly Pierella luna. Proc. Natl. Acad. Sci. USA 2014, 111, 15630-15634. [CrossRef]

14. Rebollar, E.; Sanz, M.; Pérez, S.; Hernández, M.; Martín-Fabiani, I.; Rueda, D.R.; Ezquerra, T.A.; Domingo, C.; Castillejo, M. Gold coatings on polymer laser induced periodic surface structures: Assessment as substrates for surface-enhanced Raman scattering. Phys. Chem. Chem. Phys. 2012, 14, 15699. [CrossRef] [PubMed]

15. Rebollar, E.; Hernández, M.; Sanz, M.; Pérez, S.; Ezquerra, T.A.; Castillejo, M. Laser-induced surface structures on gold-coated polymers: Influence of morphology on surface-enhanced Raman scattering enhancement. J. Appl. Polym. Sci. 2015, 132. [CrossRef]

16. Bonse, J.; Krüger, J.; Höhm, S.; Rosenfeld, A. Femtosecond laser-induced periodic surface structures. J. Laser Appl. 2012, 24, 042006. [CrossRef]

17. Gottmann, J.; Wagner, R. Sub-wavelength ripple formation on dielectric and metallic materials induced by tightly focused femto-second laser radiation. In Proc. SPIE 6101, Photon Processing in Microelectronics and Photonics V; SPIE: Santa Clara, CA, USA; 21-26 January 2006, p. 61061R.

18. Guay, J.-M.; Calà Lesina, A.; Baxter, J.; Killaire, G.; Ramunno, L.; Berini, P.; Weck, A. Topography Tuning for Plasmonic Color Enhancement via Picosecond Laser Bursts. Adv. Opt. Mater. 2018, 6, 1800189. [CrossRef]

19. Rosenkranz, A.; Hans, M.; Gachot, C.; Thome, A.; Bonk, S.; Mücklich, F. Direct Laser Interference Patterning: Tailoring of Contact Area for Frictional and Antibacterial Properties. Lubricants 2016, 4, 2. [CrossRef]

20. Bieda, M.; Siebold, M.; Lasagni, A.F. Fabrication of sub-micron surface structures on copper, stainless steel and titanium using picosecond laser interference patterning. App. Surf. Sci. 2016, 387, 175-182. [CrossRef]

21. Stärk, M.; Schlickeiser, F.; Nissen, D.; Hebler, B.; Graus, P.; Hinzke, D.; Scheer, E.; Leiderer, P.; Fonin, M.; Albrecht, M.; et al. Controlling the magnetic structure of $\mathrm{Co} / \mathrm{Pd}$ thin films by direct laser interference patterning. Nanotechnology 2015, 26, 205302. [CrossRef]

22. Lasagni, A.F. Advanced Design of Periodical Structures by Laser Interference Metallurgy in the Micro/Nano Scale on Macroscopic Areas; Shaker Verlag GmbH: Aachen, Germany, 2007.

23. Voisiat, B.; Gedvilas, M.; Indrišiūnas, S.; Račiukaitis, G. Picosecond-Laser 4-Beam-Interference Ablation as a Flexible Tool for Thin Film Microstructuring. Phys. Procedia 2011, 12, 116-124. [CrossRef]

24. Geometrische Produktspezifikation (GPS)-Oberflächenbeschaffenheit: Flächenhaft-Teil 6: Klassifizierung von Methoden zur Messung der Oberflächenbeschaffenheit; DIN EN ISO 25178-6; Deutsches Institut für Normung e.V., Beuth Verlag GmbH: Berlin, Germany, 2010.

25. Leach, R. Introduction to Surface Texture Measurement. In Optical Measurement of Surface Topography; Leach, R., Ed.; Springer Berlin Heidelberg: Berlin, Germany, 2011.

26. Purtonen, T.; Kalliosaari, A.; Salminen, A. Monitoring and Adaptive Control of Laser Processes. Phys. Procedia 2014, 56, 1218-1231. [CrossRef]

27. Smilde, H.-J.H.; den Boef, A.; Kubis, M.; Jak, M.; van Schijndel, M.; Fuchs, A.; van der Schaar, M.; Meyer, S.; Morgan, S.; Wu, J.; et al. Evaluation of a novel ultra small target technology supporting on-product overlay measurements. In Proc. SPIE 8324, Metrology, Inspection, and Process Control for Microlithography XXVI; SPIE: San Jose, CA, USA; 12-16 February 2012, p. 83241A.

28. Pollentier, I.; Cheng, S.Y.; Baudemprez, B.; Laidler, D.; van Dommelen, Y.; Carpaij, R.; Yu, J.; Uchida, J.; Viswanathan, A.; Chin, D.; et al. In-line lithography cluster monitoring and control using integrated scatterometry. In Proc. SPIE 5378, Data Analysis and Modeling for Process Control; SPIE: Santa Clara, CA, USA; 22-27 February 2004, p. 105. 
29. El Kodadi, M.; Soulan, S.; Besacier, M.; Schiavone, P. Real time scatterometry for profile control during resist trimming process. J. Vac. Sci. Technol. B 2009, 27, 3232. [CrossRef]

30. Kreuzer, M.; Whitworth, G.L.; Francone, A.; Gomis-Bresco, J.; Kehagias, N.; Sotomayor-Torres, C.M. In-line metrology for roll-to-roll UV assisted nanoimprint lithography using diffractometry. APL Mater. 2018, 6, 058502. [CrossRef]

31. Aguilar-Morales, A.I.; Alamri, S.; Kunze, T.; Lasagni, A.F. Influence of processing parameters on surface texture homogeneity using Direct Laser Interference Patterning. Opt. Laser Technol. 2018, 107, 216-227. [CrossRef]

32. Lang, V.; Rank, A.; Lasagni, A.F. Large Area One-Step Fabrication of Three-Level Multiple-Scaled Micro and Nanostructured Nickel Sleeves for Roll-to-Roll Hot Embossing: Large Area Fabrication of Three-Level microstructures. Adv. Eng. Mater. 2017, 19, 1700126. [CrossRef]

33. Athanasiou, C.-E.; Hongler, M.-O.; Bellouard, Y. Unraveling Brittle-Fracture Statistics from Intermittent Patterns Formed During Femtosecond Laser Exposure. Phys. Rev. Appl. 2017, 8, 054013. [CrossRef]

34. Boulané-Petermann, L. Processes of bioadhesion on stainless steel surfaces and cleanability: A review with special reference to the food industry. Biofouling 1996, 10, 275-300. [CrossRef]

35. Jullien, C.; Bénézech, T.; Carpentier, B.; Lebret, V.; Faille, C. Identification of surface characteristics relevant to the hygienic status of stainless steel for the food industry. J. Food Eng. 2003, 56, 77-87. [CrossRef]

36. Akl, M.A.; Ahmed, M.A.; Ramadan, A. Validation of an HPLC-UV method for the determination of ceftriaxone sodium residues on stainless steel surface of pharmaceutical manufacturing equipments. Pharm. Biomed. Anal. 2011, 55, 247-252. [CrossRef]

37. Siva Reddy, V.; Kaushik, S.C.; Ranjan, K.R.; Tyagi, S.K. State-of-the-art of solar thermal power plants-A review. Renew. Sustain. Energy Rev. 2013, 27, 258-273. [CrossRef]

38. Geometrische Produktspezifikation (GPS)-Oberflächenbeschaffenheit: Flächenhaft; DIN EN ISO 25178; Deutsches Institut für Normung e.V., Beuth Verlag GmbH: Berlin, Germany, 2012.

39. Lasagni, A.F.; Alamri, S.; Rößler, F.; Lang, V.; Voisiat, B. Design of Perfectly Ordered Periodic Structures on Polymers Using Direct Laser Interference Patterning. In Wrinkled Polymer Surfaces; González-Henríquez, C.M., Rodríguez-Hernández, J., Eds.; Springer International Publishing: Cham, Switzerland, 2019; pp. 157-180.

40. Bonse, J.; Hohm, S.; Kirner, S.V.; Rosenfeld, A.; Kruger, J. Laser-Induced Periodic Surface Structures-A Scientific Evergreen. IEEE J. Sel. Top. Quantum Electron. 2017, 23, 7581030. [CrossRef]

41. Voisiat, B.; Teutoburg-Weiss, S.; Rank, A.; Lasagni, A.F. DLIP holographic structuring: from basic concept to advanced monitoring methods and industrial scale production. In Proc. SPIE 10906, Laser-Based Micro-and Nanoprocessing XIII; Klotzbach, U., Kling, R., Watanabe, A., Eds.; SPIE: San Francisco, CA, USA, 2019; Volume 109060W, p. 31.

42. Rößler, F.; Günther, D.; Lasagni, A.F. Fabrication of Hierarchical Micro Patterns on PET Substrates Using Direct Laser Interference Patterning: Fabrication of Hierarchical Micro Patterns. Adv. Eng. Mater. 2016, 18, 1755-1762. [CrossRef]

43. Rößler, F.; Kunze, T.; Lasagni, A.F. Fabrication of diffraction based security elements using direct laser interference patterning. Opt. Express 2017, 25, 22959. [CrossRef] [PubMed]

44. Aguilar-Morales, A.I.; Alamri, S.; Lasagni, A.F. Micro-fabrication of high aspect ratio periodic structures on stainless steel by picosecond direct laser interference patterning. J. Mater. Process. Technol. 2018, 252, 313-321. [CrossRef]

45. Alamri, S.; Aguilar-Morales, A.I.; Lasagni, A.F. Controlling the wettability of polycarbonate substrates by producing hierarchical structures using Direct Laser Interference Patterning. Eur. Polym. J. 2018, 99, 27-37. [CrossRef]

46. Lang, V.; Voisiat, B.; Lasagni, A.F. High Throughput Direct Laser Interference Patterning of Aluminum for Fabrication of Super Hydrophobic Surfaces. Materials 2019, 12, 1484. [CrossRef] [PubMed]

47. Bradski, G. The OpenCV Library. Dr. Dobb's Journal of Software Tools 2000, 25, 120-125.

(C) 2019 by the authors. Licensee MDPI, Basel, Switzerland. This article is an open access article distributed under the terms and conditions of the Creative Commons Attribution (CC BY) license (http://creativecommons.org/licenses/by/4.0/). 